BMJ Open Sport \& Exercise Medicine

\title{
Narrative review of injuries in powerlifting with special reference to their association to the squat, bench press and deadlift
}

\author{
Victor Bengtsson, ${ }^{1}$ Lars Berglund, ${ }^{1,2}$ Ulrika Aasa ${ }^{1,2,3}$
}

To cite: Bengtsson V,

Berglund L, Aasa U. Narrative review of injuries in powerlifting with special reference to their association to the squat, bench press and deadlift. BMJ Open Sport \& Exercise Medicine 2018;4:e000382. doi:10.1136/ bmjsem-2018-000382

Accepted 25 June 2018

\section{Check for updates}

(c) Author(s) (or their employer(s)) 2018. Re-use permitted under CC BY-NC. No commercial re-use. See rights and permissions. Published by BMJ.

${ }^{1}$ Department of Community Medicine and Rehabilitation, Physiotherapy, Umeå University, Umeå, Sweden

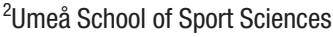
Umeå University, Umeå, Sweden ${ }^{3}$ Medfit, Primary Care Rehabilitation and Fitness Centre, Stockholm, Sweden

Correspondence to Dr Lars Berglund; lars.berglund@umu.se

\section{ABSTRACT}

Pain and injuries are considered a common problem among elite athletes and recreational lifters performing the squat, bench press and deadlift. Since all three lifts engage multiple joints and expose the lifters' bodies to high physical demands often several times a week, it has been suggested that their injuries might be related to the excessively heavy loads, the large range of motion during the exercises, insufficient resting times between training sessions and/or faulty lifting technique. However, no previous article has summarised what is known about specific injuries and the injury aetiology associated with the three lifts. Thus, the aim of this narrative review was to summarise what is known about the relationships between the powerlifting exercises and the specific injuries or movement impairments that are common among lifters and recreationally active individuals.

\section{INTRODUCTION}

Participation rates in powerlifting are generally rising among both men and women and across all ages, levels of training and/or competition. Powerlifting is a sport consisting of the squat, the bench press and the deadlift exercises. In competition, maximal loads corresponding to up to four times bodyweight are lifted for single repetitions. ${ }^{1}$ The powerlifters (hereafter called lifters) compete in classes separated by age, weight and sex. ${ }^{2}$ During training, lifters use submaximal loads but engage in higher volumes of training to stimulate hypertrophy and maximal strength. Generally, training for powerlifting is very repetitive as the three lifts, or variations of them, make up most of the exercises.

Earlier studies that have reported injury incidence and prevalence among powerlifters, ${ }^{3-8}$ as well as questionnaire studies, ${ }^{68}$ have shown that many injuries are training related: subelite to elite lifters report that $22 \%-32 \%$ of their injuries are related to the squat, $18 \%-46 \%$ to the bench press and $12 \%-31 \%$ to the deadlift exercise. Furthermore, it has been described that injuries are
What is already known?

Both acute and overuse injuries can occur in powerlifters.

- A high proportion of the injuries among powerlifters seem to occur during performance of the squat bench press and deadlift exercise.

- Both intrinsic and extrinsic factors have been reported to be associated with these injuries.

\section{What are the new findings?}

- There is limited evidence describing a relationship between the powerlifting exercises and specific injuries.

- The majority of injuries associated with the three lifts are reported in case reports.

- Most studies reported bench press injuries, with pectoralis major ruptures being the most frequently reported specific injury.

of both acute and overload character, but overuse injuries are more frequent. ${ }^{6}{ }^{8}$ It is, however, still unknown whether the injuries occur due to any of the specific demands that the squat, bench press or deadlift exercises place on the musculoskeletal system. In this regard, a recent systematic review found the squat, bench press and deadlift are some of the exercises most associated with injury among powerlifters, weightlifters, bodybuilders, CrossFit athletes and strongman athletes. ${ }^{9}$ The squat, bench press and deadlift are also used by athletes in other sports and among recreational athletes when aiming to increase their strength, muscle mass and performance. However, little is known about the relationship between the powerlifting exercises and injuries among these populations.

The squat exercise is performed with the barbell held horizontally across the back of the shoulders, and the lifter removes the barbell from the powerlifting rack and steps 
backwards. During training, the lifter then lowers the body by flexing at the hip, knee and ankle joints until the hip crease is lower than the top of the knee. Thereafter, the lifter returns to an upright position by extending the same joints. During competition, the lifter has to assume an erect, motionless posture with the knees fully extended and the torso in an upright position before receiving the SQUAT signal from the referee to initiate the descent and then return to an upright position. When the ascent is completed, the referee signals 'RACK', and the lifter returns the barbell to the rack. ${ }^{2}$ The main contributing muscles during performance of the squat are the back and hip extensors, hip adductors, hip abductors, knee extensors and ankle plantar flexors. ${ }^{10}$

For the bench press, the lifter lies supine on a bench, lifts the barbell from the powerlifting rack and holds the barbell with straight arms perpendicular to the lifter's body. During training, the lifter then lowers the barbell to the chest and then returns the barbell to the starting position either with or without a pause at the chest. During competition, the lifter holds the barbell with straight arms, and on the referee's signal, the lifter lowers the barbell to the chest. Thereafter, the lifter must pause with the barbell at the chest until he or she receives a 'PRESS' command, whereupon the barbell shall be returned to the starting position. The lifter then receives a 'RACK' command in order to mark the completion of the lift and returns the barbell to the rack. ${ }^{2}$ The bench press is performed with a grip width of no more than $81 \mathrm{~cm}$ between index fingers. The main muscles contributing to performance of the bench press are the pectoralis major, triceps brachii and the anterior deltoid muscles. ${ }^{11}$

The deadlift requires lifting the barbell off the ground until the lifter is standing erect. When assuming the starting position, the lifter usually flexes the ankles, knees and hips. During competition, the lifter grasps the barbell with straight arms, lifts the barbell and stands erect until the referee gives a 'DOWN' command, on which the barbell may be lowered to the ground. ${ }^{2}$ The prime movers during the deadlift are the hip, knee and back extensors. ${ }^{12}$ There are two main deadlifting styles: the conventional and the sumo style. With the conventional style, a narrow stance is used, and the barbell is held with the hands positioned outside of the knees. In the sumo style, generally, a wide stance is used, and the barbell is held with the hands positioned inside of the knees with the thighs more horizontally, the shanks more vertically and the feet turned out while maintaining an upright trunk. ${ }^{1314}$

Strength and conditioning professionals often work with lifters who want to know how to prevent injuries and physiotherapists often treat lifters who seek care for pain that is associated with powerlifting movements. When encountering these athletes, an understanding of the aetiology of the pain experience and injuries is important. Since all three lifts engage multiple joints and their bodies are exposed to high physical demands often several times a week, it has been suggested that their injuries might be related to the excessively heavy loads, the large range of motion during the exercises, insufficient resting times between training sessions and/ or faulty lifting technique. ${ }^{15-19}$ This narrative review will summarise what is known about the relationships between the powerlifting exercises and the specific injuries or movement impairments that are common among lifters and recreationally active individuals. Such information could establish injury prevention strategies in the sport of powerlifting and improve the rehabilitation of lifters. $^{20}$

\section{Literature search methodology}

A literature search was performed in April 2017 using the following databases: PubMed, CINAHL and SPORTDiscus using the following search strategy: (injur* OR cumulative trauma disorders OR overuse) AND (squat* OR deadlift* OR bench press* OR benchpress* OR powerlift* OR power lift*), where an asterisk symbol represents truncation. Articles were identified for potential inclusion during three stages of assessment: title, abstract and full text. In addition to the database search strategy, relevant articles previously known by the authors were added, and the reference lists of identified articles were screened to find additional articles that also satisfied the search criteria. Only English language peer-reviewed journal papers were considered. There was no limitation for publishing year or sex. Articles were identified as relevant if presenting an association between musculoskeletal injuries and the squat, bench press or deadlift powerlifting exercises among athletes and non-athletes.

\section{RESULTS}

The literature search yielded 1059 studies after removal of duplicates. Out of these, 56 were considered for inclusion after review of title and abstract. Following a full-text review, 23 studies were excluded due to not qualifying as full-text articles (two) and because they did not report an association between specific musculoskeletal injuries and the squat, bench press or deadlift powerlifting exercises. ${ }^{21}$ After reviewing the reference lists of included studies, another six studies were included. Hence, 39 studies were deemed relevant for inclusion.

Of the 39 eligible studies, there was a total of 33 case reports/case series, four retrospective cohort studies, one prospective cohort study and one meta-analysis. The number of studies reporting injuries caused by the squat, bench press and deadlift was 7, 30 and 4, respectively (figure 1).

\section{Squat-related injuries}

The literature search five case reports, ${ }^{21-25}$ one case series $^{26}$ and one retrospective study reporting injuries associated with the squat exercise (table 1). ${ }^{27}$ Most case reports included lifters with musculotendinous ruptures or avulsions: three cases of bilateral quadriceps tendon ruptures, ${ }^{21-23}$ one of them with an accompanying spiral fracture of tibia and fibula ${ }^{21}$ and another with an 


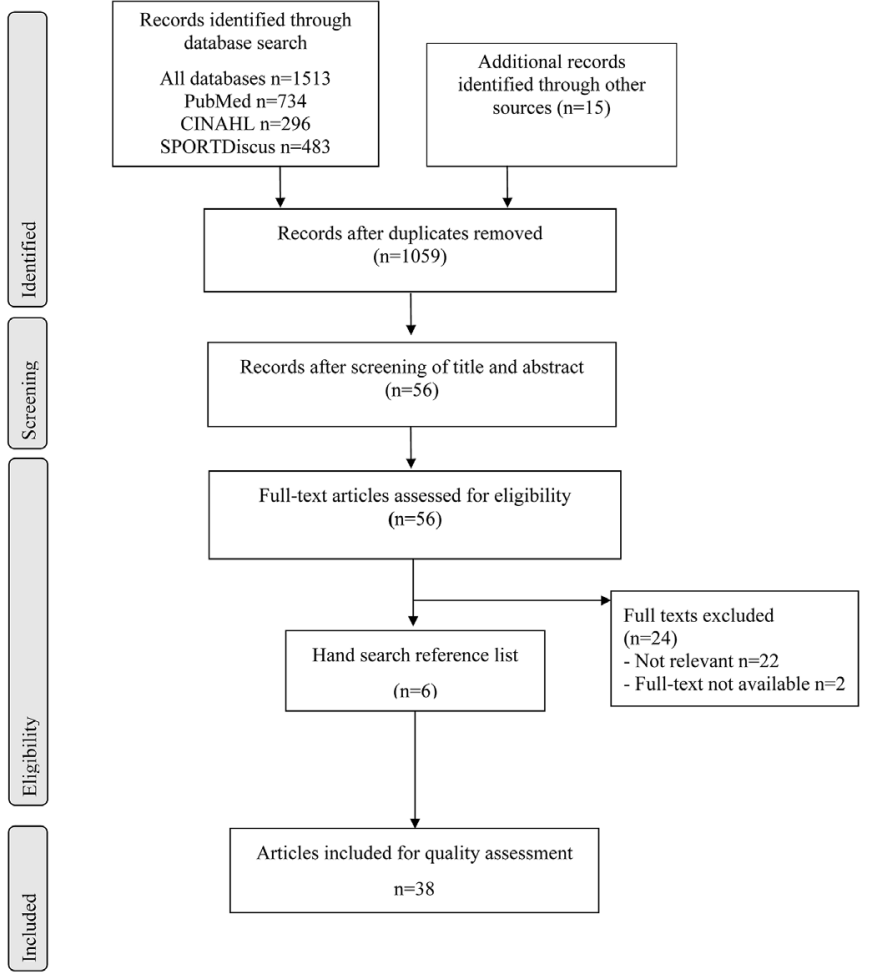

Figure 1 Flow chart of literature search.

accompanying partial ACL tear. ${ }^{22}$ Two of the case reports included lifters using anabolic steroids. ${ }^{22} 23$ The retrospective study reported an avulsion of the reflected head of the rectus femoris with a labrum tear, ${ }^{27}$ and the case series reported a ruptured biceps femoris muscle and tendon. ${ }^{26}$ However, one of those occurred 3 weeks after a hamstring syndrome operation. In addition, various fractures have been reported in people who performed the squat exercise. Specifically, a talus dome fracture ${ }^{24}$ and a Clay-shoveler's fracture (fracture of the spinous process of a lower cervical vertebra).$^{25}$

\section{Bench press-related injuries}

The literature search identified 20 case reports, ${ }^{28-47}$ 7 case series, ${ }^{48-54} 1$ retrospective study, ${ }^{55} 1$ prospective cohort $^{56}$ and 1 meta-analysis. ${ }^{57}$ Most case reports/ series reported pectoralis major ruptures caused by bench pressing (table 2). $.^{32-41} 49-53$ 55-57 The meta-analysis showed that the bench press is the most common activity leading to pectoralis major ruptures. ${ }^{57}$ Furthermore, four cases of triceps tendon ruptures were identified, ${ }^{46}$ of which three had been using oral anabolic steroids and had reported preceding chronic elbow pain before the rupture. Therefore, two of them had received local steroid injections as treatment for triceps tendinopathy some weeks before the ruptures. One case of weightlifter's shoulder (ie, osteolysis of the distal clavicle) ${ }^{47}$ and five cases of bench presser's shoulder (ie, insertional tendinopathy of the pectoralis minor muscle), ${ }^{48}$ as well as posterior ${ }^{42}$ and anterior shoulder dislocations ${ }^{28-30}$ have been described. In addition, various fractures have been reported as a consequence of the bench press: one case report described a patient who had suffered a clavicle fracture while performing the bench press ballistically $^{31}$ and another described a lifter who had suffered a scaphoid fracture when the barbell slipped out of his hand. ${ }^{45}$ Also, a second rib fracture ${ }^{43}$ and a Salter-Harris type I fracture of the distal radius have been reported. ${ }^{44}$

\section{Deadlift-related injuries}

The literature search identified a limited amount of studies describing how the deadlift exercise might be associated with specific injuries: one case report, ${ }^{58}$ two case series ${ }^{2652}$ and one retrospective study (table 3). ${ }^{59}$ All but one injury affected the lower back or lower extremities: the case report included a lifter with an acetabular stress fracture ${ }^{58}$ and the case series reported one lifter with a pectoralis major rupture ${ }^{52}$ and two lifters with hamstrings muscle ruptures. ${ }^{26}$ The retrospective study reported two lifters with avulsions of the anterior superior iliac spine, two lifters with knee meniscus injuries and four lifters with lumbosacral injuries. ${ }^{59}$

\section{DISCUSSION}

This narrative review found 7, 30 and 4 studies on the relationships between specific injuries and the squat, bench press and deadlift, respectively. No study reported the relationships between the exercises and movement impairments, although we found two clinical

Table 1 Injuries reported in studies of the squat exercise

\begin{tabular}{|c|c|c|c|}
\hline Injury & $\mathbf{n}$ & Study design & Study \\
\hline $\begin{array}{l}\text { Avulsions of the reflected head of the rectus femoris with labral } \\
\text { partial thickness tear }\end{array}$ & 1 & Retrospective study & Foote et $a l^{27}$ \\
\hline Bilateral quadriceps rupture with spiral fracture tibia and fibula & 1 & Case report & Grenier and Guimont ${ }^{21}$ \\
\hline Bilateral quadriceps rupture with partial ACL tear & 1 & Case report & Fenelon et $a l^{22}$ \\
\hline Talus bone fracture & 1 & Case report & Mannis ${ }^{24}$ \\
\hline
\end{tabular}

$\mathrm{n}$, number of participants in the study. 
Table 2 Injuries reported in studies of the bench press

\begin{tabular}{|c|c|c|c|}
\hline Injury & $\mathrm{n}$ & Study design & Study \\
\hline Bench presser's shoulder & 5 & Case series & Bhatia et a $\left.\right|^{48}$ \\
\hline Bilateral anterior shoulder dislocation & 1 & Case report & Jones $^{28}$ \\
\hline Bilateral anterior shoulder dislocation & 1 & Case report & Cresswell and Smith ${ }^{29}$ \\
\hline Bilateral anterior shoulder dislocation with Hill-Sachs lesions & 1 & Case report & El Rassi et $a l^{30}$ \\
\hline Clavicle fracture & 1 & Case report & Rijnberg and Linge ${ }^{31}$ \\
\hline Pectoralis major rupture & 1 & Case report & Ordas Bayon et a/ ${ }^{32}$ \\
\hline Pectoralis major rupture & 29 & Meta-analysis & Bak et $a l^{57}$ \\
\hline Pectoralis major rupture & 1 & Case report & Rijnberg and Linge ${ }^{33}$ \\
\hline Pectoralis major rupture & 9 & Case series & Aärimaa et a $/^{49}$ \\
\hline Pectoralis major rupture & 1 & Case report and review & Hasegawa and Schofer ${ }^{34}$ \\
\hline Pectoralis major rupture & 25 & Case series & Guity et $a l^{50}$ \\
\hline Pectoralis major rupture & 1 & Case report & Hoppes et a/ ${ }^{35}$ \\
\hline Pectoralis major rupture & 8 & Retrospective study & Schepsis et $a^{55}$ \\
\hline Pectoralis major rupture & 1 & Case report & Krishne et $a l^{36}$ \\
\hline Pectoralis major rupture & 12 & Prospective cohort & de Castro Pochini et $a^{56}$ \\
\hline Pectoralis major rupture & 6 & Case series & Kakwani et al ${ }^{51}$ \\
\hline Pectoralis major rupture & 1 & Case report & Reut et $\left.a\right|^{37}$ \\
\hline Pectoralis major rupture & 1 & Case report and review & McEntire et $a l^{39}$ \\
\hline Pectoralis major rupture & 1 & Case report & Pochini et $a /^{38}$ \\
\hline Pectoralis major rupture & 8 & Case series & Connell et a $\left.\right|^{52}$ \\
\hline Pectoralis major rupture & 14 & Case series & Garrigues et $a l^{53}$ \\
\hline Pectoralis major rupture with pectoral nerve injury & 1 & Case report & Borg-Stein et $a^{40}$ \\
\hline Pectoralis major tendon avulsion & 1 & Case report & Prabhu et al ${ }^{41}$ \\
\hline Posterior shoulder dislocation & 1 & Case report & Cuffolo et al ${ }^{42}$ \\
\hline Rib fracture & 1 & Case report & Goeser and Aikenhead ${ }^{43}$ \\
\hline Salter-Harris type I fracture of the distal radius & 1 & Case report & Weiss and Sponseller ${ }^{44}$ \\
\hline Scaphoid fracture & 1 & Case report & Mason et al ${ }^{45}$ \\
\hline Triceps tendon rupture & 1 & Case report & Herrick and Herrick ${ }^{46}$ \\
\hline Triceps tendon rupture & 3 & Case series & Sollender et $a l^{54}$ \\
\hline Weightlifter's shoulder & 1 & Case report & O’Brien ${ }^{47}$ \\
\hline
\end{tabular}

n, number of participants in the study.

commentaries that discussed feelings of instability during the bench press. ${ }^{1718}$ Regarding the squat, studies reported lower limb muscle and tendon ruptures and fractures in the neck and foot. Notably, we did not find any articles that reported injuries in the thoracic or lumbar spinal structures, although many biomechanical studies have

Table 3 Injuries reported in studies of the deadlift

\begin{tabular}{llll}
\hline Injury & $\mathbf{n}$ & Study design & Study \\
\hline Acetabular stress fracture & 1 & Case report & Karnes et al $\left.\right|^{58}$ \\
Biceps femoris rupture & 1 & Case series & Orava and Kujala ${ }^{26}$ \\
Biceps femoris and semitendinosus rupture & 1 & & \\
Pectoralis major rupture & 1 & Case series & Connell et al ${ }^{52}$ \\
ASIS avulsion & 2 & Retrospective study & Brady et a $\left.\right|^{59}$ \\
Knee meniscus injury & 2 & & \\
Lumbosacral injury & 4 & & \\
\hline
\end{tabular}

n, number of participants in the study. 
stated that the squat may cause harmful stress to the spine and sacroiliac joints ${ }^{15} 18$ and may cause spondylolysis, ${ }^{15}$ spondylolisthesis ${ }^{60}$ and ruptured intervertebral discs. ${ }^{60}$ For the bench press exercise, studies reported muscle ruptures, especially of the pectoralis major muscle, fractures of the clavicle, rib and upper extremity and osteoloysis of the acromioclavicular joint, dislocation of the glenohumeral joint and tendinopathies. Despite the fact that the deadlift exercise seems to cause the majority of powerlifting injuries, ${ }^{68}$ there is only a limited amount of research reporting the occurrence of specific injuries. However, four deadlift-related studies described fractures, muscle ruptures, various low back injuries and meniscus tear. ${ }^{26525859}$ In addition to the injuries identified in this review, it is believed that the deadlift exercise could cause spondylolysis, ${ }^{15}$ ischial apophysitis avulsions ${ }^{17}$ and damage of the vertebral ligaments, thoracolumbar fascia and dorsal rami. ${ }^{19}$

Only 3 of the 38 studies reported a suboptimal lifting technique to be the cause of injury. ${ }^{2428}{ }^{29}$ Notably, heavy $\operatorname{load}^{24}$ and fatigue ${ }^{28}{ }^{29}$ were also emphasised as contributing factors in those cases. Variations in lifting technique changes the moment arms and hence the forces acting on the primary joints. ${ }^{13}{ }^{16-68}$ It has been shown that different techniques can modulate the compressive, shear and rotational forces acting on the joints. 1316 60-63 68-73 For example, the squat is often considered a safe exercise provided it is performed correctly. ${ }^{10}{ }^{74}$ However, there is still some disagreement among researchers, coaches and athletes as to what constitutes a correct technique ${ }^{75}$ and whether aspects of technique such as squat depth, ${ }^{75}$ stance width, ${ }^{64}$ speed of movement, ${ }^{72}$ barbell positioning $^{68}$ and direction of gaze ${ }^{71}$ influence risk of injury and to what extent the lifting technique is modified by fatigue. ${ }^{70}$ Three categories of biomechanical outcomes have primarily been studied: (A) the tibiofemoral compression and shear, and patellofemoral compression, (B) muscle activity of the quadriceps and hamstrings and (C) anteroposterior and mediolateral knee stability. ${ }^{60}$ Regarding the compressive and shear forces, it has been shown that they increase as knee flexion increases. ${ }^{63}$ Of great concern is also the stress on the structures in and around the knee joint when performing the squat with simultaneous knee flexion, hip adduction and internal rotation of the femur (valgus stress). ${ }^{60} 61$ Special attention has been given to squat depth since a deeper squat increases load on the hip and knee joints, ${ }^{68}$ provided that the same weight is used. Regarding stance width, an excessively wide stance may increase patellofemoral and tibiofemoral compressive forces, while a narrow stance increases the anterior shear forces as a result of anterior knee translation. ${ }^{60616369}$ Concerning speed of movement, a higher lifting speed increases anteroposterior shear and compressive forces at the knee joint. ${ }^{72}$ Moreover, a bouncing movement at the bottom of the squat has been shown to increase the shear forces at the knee joint ${ }^{71}$ and a rapid and uncontrolled descent is said to produce excessive strain and shear forces to the cruciate and collateral ligaments that could damage these structures. ${ }^{76}$ Also the posture of the spine is affected by faster lifting speed: a greater forward lean has been shown during repetitive squatting ( $>10$ repetitions) at fast speed. ${ }^{70} \mathrm{~A}$ greater forward lean has been associated with increased lumbar shear forces, ${ }^{70}$ and the fast speed has been associated with higher compressive forces during squatting. ${ }^{72}$ Notably, however, the importance of lifting technique on spinal load may vary between studies depending on which method was used for estimating the load. ${ }^{77}$ Regarding the barbell positioning, a high bar position is thought to shift some of the load from the hips to the knees. ${ }^{68}$ As for the direction of gaze, a downward gaze compared with an upward and straight gaze has been found to increase hip flexion and a trend towards increased trunk flexion. ${ }^{71}$

The bench press, as it is performed during powerlifting training, is generally considered a potential risk factor for developing injuries to the shoulder area. ${ }^{16}$ The reason for this belief is often explained with the fact that the lift involves high loads of the shoulder in outer range positions. As with the squat, there is some disagreement among researchers, coaches and athletes as to what constitutes a correct technique and whether aspects of technique such as grip width, shoulder position and arching of the spine influence risk of injury. The major mechanisms of injury suggested within the literature are: grip width $>1.5 \times$ biacromial width, high or intolerable exercise dose or repetitive strain and altered proprioception (postinjury). ${ }^{16}$ Biomechanical studies have highlighted that using a wide grip puts the shoulder joint in a disadvantageous position stressing the acromioclavicular joint, glenohumeral ligaments and the pectoralis major muscle. ${ }^{66}$ Additionally, provided that the shoulder abduction/extension angle remains the same, a wider grip increases the shoulder torque which, in turn, increases the requirements on the rotator cuff and biceps tendon complex stabilising the humeral head. ${ }^{67}$ However, using a wide grip of $165 \%-200 \%$ of biacromial width is preferable for bench press performance since this allows the lifter to handle heavier weights compared with both narrower and wider grip widths. ${ }^{65}$ Earlier research has shown that experienced lifters use a wider grip than novices, potentially because it gives the lifter a biomechanical advantage with shorter vertical bar path. ${ }^{66}$ This practice is also recommended by some authors in the context of minimising risk of injury to the shoulder complex by minimising range of motion..$^{15} 7879$ Besides the mentioned technical variations influence on potential risk of injury, losing control of the barbell has been put forward as a mechanism of injury regarding fractures and shoulder dislocations that have been reported in several studies. ${ }^{28} 29$

Regarding the deadlift, a more upright torso preserving lumbar lordosis is believed to reduce the injury risk. ${ }^{14} 73$ Also, keeping the barbell close to the body is important for improving performance and reducing the risk of injury since this decreases the hip and spinal moment arms. ${ }^{14}$ Regarding the knees, it is said to be important not 
to extend the knees prematurely or excessively in order to avoid what is referred to as a 'stiff-leg' deadlift, which occurs when knees are near or at full extension. ${ }^{13}{ }^{14}$ This decreases quadriceps activity and increases hamstrings and erector spinae activity ${ }^{13}$ but perhaps, more importantly, causes a less upright torso position. ${ }^{73}$ Furthermore, since the forces exerted on the lifters' joints differ depending on lifting style, many studies have focused on analysing the consequences of lifting style. ${ }^{12-1473}$ For example, in the sumo style, the lifter can maintain a more upright torso, thus supporting the argument that it is easier to maintain lumbar lordosis using the sumo style. ${ }^{62}$ This does not seem to influence compressive forces on the $\mathrm{L} 4 / \mathrm{L} 5$ disc $^{73}$ but decreases the L4/L5 moment and shear forces compared with the conventional stance. ${ }^{73}$ Instead, the ankle dorsiflexor and knee moments and moment arms are relatively larger with the sumo style compared with the conventional style. ${ }^{13}$

In close association with lifting technique, the load itself is often considered an important risk factor in the development of injury. Especially, the combination of high loads and improper technique is said to increase the risk of injury. ${ }^{17}$ Fatigue has previously been implicated as a contributing factor to sporting injury ${ }^{80}$ and has been shown to impact lifting technique. ${ }^{70}$ Therefore, a strategy to reduce the risk of injury in powerlifting athletes might be to perform the most demanding exercises immediately after the warm-up during the initial part of their training session, as done by most powerlifters. However, no study has investigated the specific relevance of training loads, acute or chronic, as a risk factor for injuries.

Additional intrinsic factors, such as sex, competitive standard (eg, national and international levels), age and bodyweight class have been mentioned as factors that may influence injury occurrence, although very few studies have included these factors in their analyses. Still, sex seem to impact the anatomical localisation of injury. ${ }^{68}$ Women lifters report significantly more injuries in the neck, thoracic region ${ }^{8}$ and hand/wrist, ${ }^{3}$ while men seem to have higher rates of chest and thigh injuries. ${ }^{6}$ Women also seem to get injured earlier in their career than men. ${ }^{8}$ Regarding age, injury frequency does not seem to differ between open and master class athletes, that is, <40 vsersus $>40$ years, although master class athletes reported significantly more shoulder, elbow and hand/wrist injuries. $^{3}$

Of note is that the injuries have been described in terms of subjective symptoms or pathoanatomic changes. So far, associated movement impairments have only been described in two previous articles. ${ }^{17} 18$ Optimal neuromuscular control of the lifting is required in order to distribute the load evenly across each joint and minimise potentially harmful forces. Non-optimal neuromuscular control is often referred to as movement system impairments. ${ }^{81}$ For physiotherapists and strength and conditioning coaches, a more detailed description of the lifters' functional impairments might add information to how to avoid pain during the exercises. First, the therapists need to know whether the exercise that is related to the symptoms is performed with non-optimal movement patterns (technique) ${ }^{81}$ It is also important to analyse whether the lifter's movement pattern is an adaptive or maladaptive response to pain experience ${ }^{81}$ and whether optimising/changing the movement pattern decreases the pain experience. If changing the movement pattern decreases the pain, the movement system impairments causing the non-optimal movement pattern need to be retrained ${ }^{82}$ In fact, this was highlighted by the lifters themselves in a questionnaire study of injuries in powerlifting, where they attributed their injuries to faulty lifting technique in combination with excessive loads. ${ }^{8}$

\section{Methodological considerations}

Currently, many of the studies available for this review were retrospective questionnaire studies or case reports. These are important, but knowledge about bodily conditions, clinical outcome and aspects of lifting technique were infrequently (if at all) reported in the included studies. Information about training frequency, number of sets and repetitions, exercise performed and loads used would also have been useful. Such data (if involving a large enough sample of athletes over a sufficient period of time) may allow some insight into how alterations in anthropometric profile, flexibility and muscular strength/endurance imbalances and muscle recruitment pattern (intrinsic factors), extrinsic factors, for example, use of weight belts ${ }^{3}$ and fatigue ${ }^{70}$ and exercise technique (inciting events) (Sjöberg et al, 2018, unpublished data) may modulate injury risk. We also recommend that future studies include a kinesiopathological or movement-based diagnosis and/or medical examination of the powerlifting athletes to confirm diagnosis, and which includes both localisation of pain, pain symptoms and movement impairments. Furthermore, it should be noted that most recommendations regarding safe lifting techniques are based on assumptions drawn from mentioned biomechanical studies ${ }^{13} 1416$ 60-63 68-73 and that there is no evidence that exposure to one risk factor, such as large anterior knee displacement in the squat, leads to knee pain.

Lastly, despite the broad search strategy applied over several electronic databases and the screening of reference lists of identified articles, we may have missed some relevant studies. Also, by limiting the search to English language publications, we potentially missed additional relevant articles in other languages.

\section{CONCLUSION}

Although there is a common conception among practitioners and researchers that the squat, bench press and deadlift exercises are associated with sports injuries, we found limited evidence for this largely because most identified studies were case reports and very few prospective longitudinal studies have been published.

Most studies reported specific bench press injuries such as pectoralis major ruptures. We were not able to 
draw any conclusions regarding possible preventive strategies since the aetiology behind the injuries cannot be described from case studies. Future studies need to focus on injury rates and collect information about both extrinsic factors (eg, training intensity) as well as intrinsic factors (eg, age, bodyweight and sex).

Contributors UA and LB contributed to the conception of the study. All authors contributed to the design. VB contributed with data acquisition and analysis as well as being engaged as first author and drafting the work. All authors contributed to finishing the manuscript from the first draft. All authors agree to be accountable for all aspects of the work.

Funding The authors have not declared a specific grant for this research from any funding agency in the public, commercial or not-for-profit sectors.

Competing interests None declared.

Patient consent Not required.

Provenance and peer review Not commissioned; externally peer reviewed.

Open access This is an Open Access article distributed in accordance with the Creative Commons Attribution Non Commercial (CC BY-NC 4.0) license, which permits others to distribute, remix, adapt, build upon this work non-commercially, and license their derivative works on different terms, provided the original work is properly cited and the use is non-commercial. See: http://creativecommons.org/ licenses/by-nc/4.0/

\section{REFERENCES}

1. International Powerlifting Federation. Records [Internet]. 2018. http:// www.powerlifting-ipf.com/championships/records.html

2. International Powerlifting Federation. Technical Rules Book [Internet]. 2016. https://www.powerlifting-ipf.com/rulescodesinfo/technicalrules.html

3. Siewe J, Rudat J, Röllinghoff M, et al. Injuries and overuse syndromes in powerlifting. Int $J$ Sports Med 2011;32:703-11.

4. Raske A, Norlin R. Injury incidence and prevalence among elite weight and power lifters. Am J Sports Med 2002;30:248-56.

5. Brown EW, Kimball RG. Medical history associated with adolescent powerlifting. Pediatrics 1983;72:636-44.

6. Keogh J, Hume PA, Pearson S. Retrospective injury epidemiology of one hundred one competitive Oceania power lifters: the effects of age, body mass, competitive standard, and gender. J Strength Cond Res 2006;20:672-81.

7. Aasa U, Svartholm I, Andersson F, et al. Injuries among weightlifters and powerlifters: a systematic review. Br J Sports Med 2017;51:211-9.

8. Strömbäck E, Aasa U, Gilenstam K, et al. Prevalence and Consequences of Injuries in Powerlifting: A Cross-sectional Study. Orthop J Sports Med 2018;6:2325967118771016.

9. Keogh JWL, Winwood PW. The Epidemiology of Injuries Across the Weight-Training Sports. Sports Medicine 2017;47:479-501.

10. Clark DR, Lambert MI, Hunter AM. Muscle Activation in the Loaded Free Barbell Squat. J Strength Cond Res 2012;26:1169-78.

11. Clemons JM, Aaron C. Effect of Grip Width on the Myoelectric Activity of the Prime Movers in the Bench Press. J Strength Cond Res 1997;11:82-7.

12. Escamilla R, Francisco A, Kayes A, et al. An electromyographic analysis of sumo and conventional style deadlifts. Med Sci Sports Exerc 2002;34:682-8.

13. Escamilla RF, Francisco AC, Fleisig GS, et al. A three-dimensional biomechanical analysis of sumo and conventional style deadlifts. Med Sci Sports Exerc 2000;32:1265-75.

14. Escamilla RF, Lowry TM, Osbahr DC, et al. Biomechanical analysis of the deadlift during the 1999 Special Olympics World Games. Med Sci Sports Exerc 2001;33:1345-53.

15. Lavallee ME, Balam T. An overview of strength training injuries: acute and chronic. Curr Sports Med Rep 2010;9:307-13.

16. Green CM, Comfort P. The Affect of Grip Width on Bench Press Performance and Risk of Injury. Strength Cond J 2007;29:10-14

17. Reeves RK, Laskowski ER, Smith J. Weight training injuries: part 1: diagnosing and managing acute conditions. Phys Sportsmed 1998;26:67-96.

18. Reeves RK, Laskowski ER, Smith J. Weight training injuries: part 2: diagnosing and managing chronic conditions. Phys Sportsmed 1998;26:54-73.
19. Gotshalk L. Sports Performance Series: Analysis of the deadlift. National Strength \& Conditioning Association Journal 1984;6:4-9.

20. van Mechelen W, Hlobil H, Kemper HC. Incidence, severity, aetiology and prevention of sports injuries. A review of concepts. Sports Med 1992;14:82-9.

21. Grenier R, Guimont A. Simultaneous bilateral rupture of the quadriceps tendon and leg fractures in a weightlifter. Am J Sports Med 1983;11:451-3.

22. Fenelon C, Dalton DM, Galbraith JG, et al. Synchronous quadriceps tendon rupture and unilateral $A C L$ tear in a weightlifter, associated with anabolic steroid use. BMJ Case Rep 2016:bcr2015214310.

23. Hill JA, Suker JR, Sachs K, et al. The athletic polydrug abuse phenomenon. A case report. Am J Sports Med 1983;11:269-71.

24. Mannis $\mathrm{Cl}$. Transchondral fracture of the dome of the talus sustained during weight training. Am J Sports Med 1983;11:354-6.

25. Herrick RT. Clay-shoveler's fracture in power-lifting. A case report. Am J Sports Med 1981;9:29-30.

26. Orava $S$, Kujala UM. Rupture of the Ischial Origin of the Hamstring Muscles. Am J Sports Med 1995;23:702-5.

27. Foote CJ, Maizlin ZV, Shrouder J, et al. The association between avulsions of the reflected head of the rectus femoris and labral tears. $J$ Pediatr Orthop 2013;33:227-31.

28. Jones M. Bilateral anterior dislocation of the shoulders due to the bench press. Br J Sports Med 1987;21:139.

29. Cresswell TR, Smith RB. Bilateral anterior shoulder dislocations in bench pressing: an unusual cause. Br J Sports Med 1998;32:71-2.

30. El Rassi G, Hijjawi A, Matta J, et al. Bilateral locked anterior shoulder dislocation in a bench-pressing athlete: case report. Arch Orthop Trauma Surg 2015;135:747-9.

31. Gill IPS, Mbubaegbu C. Fracture shaft of clavicle, an indirect injury from bench pressing. Br J Sports Med 2004;38:e26.

32. Ordas Bayon A, Sandoval E, Valencia Mora M. Acute pectoralis major rupture captured on video. Case Rep Orthop 2016;2016:1-4.

33. Rijnberg WJ, Van Linge B. Rupture of the pectoralis major muscle in body-builders. Arch Orthop Trauma Surg 1993;112:104-5.

34. Hasegawa K, Schofer JM. Rupture of the pectoralis major: a case report and review. J Emerg Med 2010;38:196-200.

35. Hoppes CW, Ross MD, Moore JH. Undetected pectoralis major tendon rupture in a patient referred to a physical therapist in a combat environment: a case report. Phys Ther 2013;93:1225-33.

36. Urs ND, Jani DM. Surgical repair of rupture of the pectoralis major muscle: a case report. J Trauma 1976;16:749-50.

37. Reut RC, Bach BR, Johnson C. Pectoralis major rupture: diagnosing and treating a weight-training injury. Phys Sportsmed 1991;19:89-96.

38. Pochini AC, Ejnisman B, Andreoli CV, et al. Exact moment of tendon of pectoralis major muscle rupture captured on video. Br J Sports Med 2007;41:618-9.

39. McEntire JE, Hess WE, Coleman SS. Rupture of the pectoralis major muscle. A report of eleven injuries and review of fifty-six. $J$ Bone Joint Surg Am 1972;54:1040-6.

40. Borg-Stein J, Mostoufi SA, Hirschberg R. Chronic pectoral pain following medial pectoral nerve injury: A case report. J Back Musculoskelet Rehabil 2006;19:7-11.

41. Prabhu J, Faqi MK, Alkhalifa F, et al. Repair of Double Head Pectoralis Major Tendon Avulsion into its Native Footprint Using Bicortical EndoButtons and Tendon Sliding Technique. Open Orthop J 2017; $11: 12-19$

42. Cuffolo G, Coomber R, Burtt S, et al. Posterior shoulder dislocation while lifting weights: a missed diagnosis. BMJ Case Rep 2014;2014:bcr2013202156.

43. Goeser CD, Aikenhead JA. Rib fracture due to bench pressing. $J$ Manipulative Physiol Ther 1990;13:26-9.

44. Weiss AP, Sponseller PD. Team physician \#5. Salter-Harris type I fracture of the distal radius due to weightlifting. Orthop Rev 1989;18:233-5.

45. Mason JS, Crowell MS, Goss DL. Fracture of the Scaphoid During a Bench-Press Exercise. J Orthop Sports Phys Ther 2015;45:642.

46. Herrick RT, Herrick S. Ruptured triceps in a powerlifter presenting as cubital tunnel syndrome. Am J Sports Med 1987;15:514-6.

47. O'brien SA. Osteolysis of the distal clavicle: an important consideration in chronic shoulder pain. J Can Chiropr Assoc 1987;31:31-2.

48. Bhatia DN, de Beer JF, van Rooyen KS, et al. The "bench-presser's shoulder": an overuse insertional tendinopathy of the pectoralis minor muscle. Br J Sports Med 2007;41:e11.

49. Äärimaa V, Rantanen J, Heikkilä J, et al. Rupture of the pectoralis major muscle. Am J Sports Med 2004;32:1256-62.

50. Guity M, Sharafat Vaziri A, Shafiei $\mathrm{H}$, et al. Surgical treatment of pectoralis major tendon rupture (outcome assessment). Asian $\mathrm{J}$ Sports Med 2014;5:129-35. 
51. Kakwani RG, Matthews JJ, Kumar KM, et al. Rupture of the pectoralis major muscle: Surgical treatment in athletes. Int Orthop 2007;31:159-63.

52. Connell DA, Potter HG, Sherman MF, et al. Injuries of the pectoralis major muscle: evaluation with MR imaging. Radiology 1999;210:785-91.

53. Garrigues GE, Kraeutler MJ, Gillespie RJ, et al. Repair of pectoralis major ruptures: single-surgeon case series. Orthopedics 2012;35:e1 184-e1190.

54. Sollender JL, Rayan GM, Barden GA. Triceps tendon rupture in weight lifters. J Shoulder Elbow Surg 1998;7:151-3.

55. Schepsis AA, Grafe MW, Jones HP, et al. Rupture of the Pectoralis Major Muscle. Am J Sports Med 2000;28:9-15.

56. de Castro Pochini A, Ejnisman B, Andreoli CV, et al. Pectoralis Major Muscle Rupture in Athletes. Am J Sports Med 2010;38:92-8.

57. Bak K, Cameron EA, Henderson IJP. Rupture of the pectoralis major: a meta-analysis of 112 cases. Knee Surgery, Sports Traumatology, Arthroscopy 2000;8:113-9.

58. Karnes JM, Hagedorn JC, Hubbard DF. Catastrophic Failure of an Acetabular Stress Fracture in a Healthy Male Power Lifter. Am J Sports Med 2015;43:2559-63.

59. Brady TA, Cahill BR, Bodnar LM. Weight training-related injuries in the high school athlete. Am J Sports Med 1982;10:1-5.

60. Schoenfeld BJ. Squatting Kinematics and Kinetics and Their Application to Exercise Performance. J Strength Cond Res 2010;24:3497-506.

61. Swinton PA, Lloyd R, Keogh JWL, et al. A Biomechanical Comparison of the Traditional Squat, Powerlifting Squat, and Box Squat. J Strength Cond Res 2012;26:1805-16.

62. Hales M. Improving the Deadlift: Understanding Biomechanical Constraints and Physiological Adaptations to Resistance Exercise. Strength Cond J 2010;32:44-51.

63. Escamilla RF. Knee biomechanics of the dynamic squat exercise. Med Sci Sports Exerc 2001;33:127-41.

64. Escamilla RF, Fleisig GS, Lowry TM, et al. A three-dimensional biomechanical analysis of the squat during varying stance widths. Med Sci Sports Exerc 2001;33:984-98.

65. Wagner LL, Evans SA, Weir JP, et al. The effect of grip width on bench press performance. International Journal of Sport Biomechanics 1992;8:1-10.

66. Madsen N, McLaughlin T. Kinematic factors influencing performance and injury risk in the bench press exercise. Med Sci Sports Exerc 1984;16:376-81.

67. Fees M, Decker T, Snyder-Mackler L, et al. Upper extremity weighttraining modifications for the injured athlete. A clinical perspective. Am J Sports Med 1998;26:732-42.
68. Wretenberg P, Feng Y, Arborelius UP. High- and low-bar squatting techniques during weight-training. Med Sci Sports Exerc 1996;28:218-24.

69. Fry AC, Smith JC, Schilling BK. Effect of knee position on hip and knee torques during the barbell squat. J Strength Cond Res 2003;17:629-33.

70. Hooper DR, Szivak TK, Comstock BA, et al. Effects of fatigue from resistance training on barbell back squat biomechanics. J Strength Cond Res 2014;28:1127-34.

71. Donnelly DV, Berg WP, Fiske DM. The effect of the direction of gaze on the kinematics of the squat exercise. J Strength Cond Res 2006;20:145-50.

72. Hattin HC, Pierrynowski MR, Ball KA. Effect of load, cadence, and fatigue on tibio-femoral joint force during a half squat. $\mathrm{Med} \mathrm{Scl}$ Sports Exerc 1989;21:613-8.

73. Cholewicki J, McGill SM, Norman RW. Lumbar spine loads during the lifting of extremely heavy weights. Med Sci Sports Exerc 1991;23:1179-86.

74. Chandler TJ, Stone MH. The squat exercise in athletic conditioning: a review of the literature. National Strength and Conditioning Association Journal 1991;13:51-8.

75. Hartmann H, Wirth K, Klusemann M. Analysis of the load on the knee joint and vertebral column with changes in squatting depth and weight load. Sports Med 2013;43:993-1008.

76. Shankman GA. Injuries: Training related injuries in progressive resistive exercise programs. National Strength \& Conditioning Association Journal 1984;6:36-7.

77. Dreischarf M, Rohlmann A, Graichen F, et al. In vivo loads on a vertebral body replacement during different lifting techniques. $J$ Biomech 2016;49:890-5.

78. Kolber MJ, Beekhuizen KS, Cheng MS, et al. Shoulder injuries attributed to resistance training: a brief review. J Strength Cond Res 2010;24:1696-704.

79. Haupt HA. Upper extremity injuries associated with strength training. Clin Sports Med 2001;20:481-90.

80. Gabbett TJ, Domrow N. Relationships between training load, injury, and fitness in sub-elite collision sport athletes. J Sports Sci 2007;25:1507-19.

81. Sahrmann SA. The human movement system: our professional identity. Phys Ther 2014;94:1034-42.

82. Aasa B, Berglund L, Michaelson P, et al. Individualized low-load motor control exercises and education versus a high-load lifting exercise and education to improve activity, pain intensity, and physical performance in patients with low back pain: a randomized controlled trial. J Orthop Sports Phys Ther 2015;45:77-85. 